\title{
Finding the event structure of neuronal spike trains
}

\author{
Vincent J Toups ${ }^{1}$, Jean-Marc Fellous ${ }^{2}$, Peter J Thomas $s^{3,4}$, Terrence J Sejnowski ${ }^{5,6}$, Paul H Tiesinga ${ }^{1,7^{*}}$ \\ From Twentieth Annual Computational Neuroscience Meeting: CNS*2011 \\ Stockholm, Sweden. 23-28 July 2011
}

Neurons in sensory systems convey information about physical stimuli in their spike trains. In vitro, single neurons respond precisely and reliably to the repeated injection of the same fluctuating current, producing regions of elevated firing rate, termed events. Analysis of these spike trains reveals that multiple distinct spike patterns can be identified as trial-to-trial correlations between spike times [1]. Finding events in data with realistic spiking statistics is challenging because events belonging to different spike patterns may overlap. We propose a method for finding spiking events that uses contextual information to disambiguate which pattern a trial belongs to. The procedure can be applied to spike trains of the same neuron across multiple trials to detect and separate responses obtained during different brain states. The procedure can also be applied to spike trains from multiple simultaneously recorded neurons in order to identify volleys of near synchronous activity or to distinguish between excitatory and inhibitory neurons. The procedure was tested using artificial data as well as recordings in vitro in response to fluctuating current waveforms.
${ }^{5}$ Howard Hughes Medical Institute, The Salk Institute, La Jolla, CA 92037, USA. ${ }^{6}$ Division of Biological Sciences, University of California San Diego, La Jolla, CA 92037, USA. ${ }^{7}$ Donders Institute for Brain, Cognition and Behaviour, Radboud University Nijmegen, Nijmegen, 6525 AJ, The Netherlands.

Published: 18 July 2011

\section{Reference}

1. Fellous JM, Tiesinga PHE, Thomas PJ, Sejnowski TJ: Discovering Spike Patterns in Neuronal Responses. Journal of Neurosci 2004, 24:2989-3001.

doi:10.1186/1471-2202-12-S1-P333

Cite this article as: Toups et al:: Finding the event structure of neuronal spike trains. BMC Neuroscience 2011 12(Suppl 1):P333.

\section{Acknowledgements}

This research was supported in part by the National Institutes of Health (R01-MH68481); the Human Frontier Science Program (JVT \& PHT); the National Science Foundation (DMS-0720142) (PJT), and the Howard Hughes Medical Institute (TJS). PJT acknowledges research support from the Oberlin College Library.

\section{Author details}

'Department of Physics \& Astronomy, University of North Carolina, Chapel Hill, NC 27599, USA. ${ }^{2}$ Psychology Department, University of Arizona, Tucson, AZ 85721, USA. ${ }^{3}$ Departments of Mathematics, Biology and Cognitive Science, Case Western Reserve University, Cleveland, OH 44106, USA. ${ }^{4}$ Department of Neuroscience, Oberlin College, Oberlin, OH 44074, USA.

\footnotetext{
* Correspondence: p.tiesinga@science.ru.nl

'Department of Physics \& Astronomy, University of North Carolina, Chapel Hill, NC 27599, USA

Full list of author information is available at the end of the article
}

Submit your next manuscript to BioMed Central and take full advantage of:

- Convenient online submission

- Thorough peer review

- No space constraints or color figure charges

- Immediate publication on acceptance

- Inclusion in PubMed, CAS, Scopus and Google Scholar

- Research which is freely available for redistribution
C Biomed Central

() 2011 Toups et al; licensee BioMed Central Ltd. This is an open access article distributed under the terms of the Creative Commons Attribution License (http://creativecommons.org/licenses/by/2.0), which permits unrestricted use, distribution, and reproduction in any medium, provided the original work is properly cited. 